\title{
Readers building fictional worlds: Visual representations, poetry, and cognition
}

\section{Introduction}

In this article, I outline how one teacher worked to demystify the processes of reading literature, and to support students in developing responses to poetry in their own terms and through discussion with their peers. Framing my study within the cognitive linguistic framework Text World Theory (Werth, 1999; Gavins, 2007), I examine the teacher's role as facilitator and mediator of reading and provide examples of students' initial interactions with the William Carlos William's poem 'The red wheelbarrow'. Specifically, this article analyses part of a teaching sequence where the teacher had asked students to produce visual representations of their initial responses to a poem to encourage a more active and less teacher-led role when engaging with literature, and to generally develop students' metacognition in relation to the reading process itself. This article is organised in the following way. First, I describe the tension that exists between understanding the value of literature teaching in the classroom and the practical reality of poetry teaching. I then provide an overview of Text World Theory, focusing in particular on the concept of the discourse-world as a rich contextual space within which meanings are formed. Following this overview, I discuss the use of visual representations before contextualising and analysing three examples of student work. The article ends with a consideration of the usefulness of such an approach and some implications for the literature classroom. 


\section{Reading and teaching literature}

The benefits to young people of reading literature are well documented. The belief in the transformational power of reading literature and its important role in developing children's imaginative, linguistic and social skills remains a central motivating factor in English teachers' decisions for entering the profession and working with young people in the classroom (Goodwyn, 1997, 2010). Research within the field of literacy studies has demonstrated that reading literature supports personal and social development and increases overall attainment across a range of school subjects (Clark and Rumbold, 2006; Clark, 2011; Sullivan and Brown, 2015). Drawing on a series of interviews with young readers, Cliff Hodges (2010) argues that readers view their engagement with literature as a dynamic process which involves them making various switches between real and fictional worlds and investing their own emotional energies while receiving significant aesthetic and cognitive payback (see also Dungworth et al., 2004; Cremin 2007). From a different perspective and set of methodological and theoretical lenses, recent advances in the cognitive humanities and social sciences have influenced experimental studies and empirical evidence that have shown the tangible benefits of reading literature in supporting the development of theory of mind (Zunshine, 2006; Kidd and Castano, 2013), empathetic skills (Mar and Oatley, 2008; Djikic et al., 2009) and pro-social behaviour (Johnson, 2012). Researchers in cognitive literary studies and cognitive stylistics on textuality have shown how the language of literary fiction can trigger a range of emotions and personal responses in readers. This important work has now become a substantive area of study in the fields of education and literacy studies; for a good recent overview of work in the context of English education, see Alsup (2015). 
There is, however, a clear tension between such fundamentally held beliefs about literature teaching and the ways in which the school system, the context of examination-driven learning and the constraints of an accountability regime can overly influence what happens in classrooms (see for example Hennessey and McNamara, 2011). Xerri (2013) argues that the assessment system has had a particularly negative influence on the teaching of poetry, where high-stakes testing has meant that students are often unable or unwilling to realise their role in the process of meaning-making and the construction of knowledge. Xerri suggests that in many cases, teachers and students are content to see poetry as a kind of puzzle holding an objective meaning that is simply there to be extracted. The student's role is consequently downplayed and even delegitimised; in contrast the teacher acts as a kind of 'gatekeeper to meaning' (2013, p.135), offering authoritative and accepted ways of thinking about and reading texts. Teachers can also defer authority in terms of their own readings of poetry and their pedagogical approaches, inevitably to examination-board materials rather than to theoretical, research-based and pedagogical outputs on the teaching of literature (Benton, 1999; and see Clark et al., 2014 for details of discussions in this respect with Post-16 English teachers). This deference can result in both teachers and students becoming resistant in various ways to poetry (Snapper, 2013).

\section{Text World Theory}

Text World Theory (see Gavins, 2007 for a comprehensive yet accessible introduction) is a cognitive discourse grammar that offers a highly principled and 
structured set of parameters to account for how meanings are constructed. In the model, real world entities termed discourse-world participants create mental representations or text-worlds of what they read or hear. These text-worlds are triggered by textual cues and are fleshed out and enriched by schematic knowledge in the form of cognitive schemas, packages of experiences and social interactions that have taken place over time. Text-worlds are dynamic structures that may be updated via details of actions, events and representations of states of being, or may be reconfigured to provide a different perspective or time frame through shifts in modality, viewpoint or tense (see Werth, 1999, p. 213-258). In turn, schemas have elements which are both highly idiosyncratic and personal, and social and intersubjective (Werth 1999, p. 96-97) and consequently help to build representations that have aspects of the unique and the shared. In all cases, participants are also constrained by specific elements in the discourse-world, a representation of the immediate context, which influences the ways in which they construct text-worlds. These elements include the time and location of the discourse, and the various degrees of knowledge of the discourse participants together with what is directly and indirectly perceptible to them from their physical environment.

As any communicative practice proceeds within the discourse-world, participants draw on the immediate context to construct a 'Common Ground' (Werth 1999, p.117), a set of facts about which they agree to be relevant to the discourse and which acts as a platform for the sharing and mutual understanding of information. This Common Ground is dynamic in so far as it changes to accommodate new information as it is negotiated and accepted by discourse-world participants. The emphasis on the negotiated nature of discourse means that personal mental representations of context 
will always be governed to a greater or lesser extent by what the discourse-world participants agree is salient. Text-world theorists therefore understand context as essentially a mental process (Edwards and Mercer, 1987) and a subjective mental model (van Dijk, 2009) rather than an objective set of physical surroundings and actions. In other words, contexts are shaped and reshaped by people interacting in time and space, and in turn are influenced by the knowledge those people hold and their stances towards the communicative situation they find themselves in.

\section{Reading in the classroom}

In the vast majority of solitary reading practices, the discourse-world participants are the author and reader, usually separated in time and space and therefore occupying a 'split discourse-world' (Gavins 2007, p. 26). In the classroom, however, the situation is more complex since there are potentially multiple discourse-world participants, namely other students, the teacher and any other supporting adults. Usually, teachers and students as primary discourse-world participants in the context of the classroom do not have equal status (Summers, 1991; Edwards and Westgate, 1994) since the social structure of the school as an institution with its inherent and embedded hierarchies means that they occupy different subject positions. The relationship between teacher and student(s) may therefore be understood as an example of what Fairclough (2014, p.36) terms an 'unequal encounter'. In the context of the classroom, the teacher as a powerful participant has the ability to apply various constraints (Fairclough 2014, p.39) on students' contributions in terms of what is said and when it is said. It is also possible to extend Fairclough's term to account for how a teacher may either emphasise or downplay different types of knowledge in the classroom, 
giving prominence to certain ways of approaching and discussing reading. In Giovanelli and Mason (2015), we argue that this foregrounding often manifests itself in the form of a 'pre-figuring' $(2015$, p. 46) where teachers are able to select and organise both contextual and paratextual information and knowledge and thereby privilege specific types of interpretation. Invariably, these readings are authorised by the teacher, whose own knowledge means that they hold a significantly richer body of knowledge, or narrative schema (see Mason, 2015), about the text being studied. Since the teacher is a more powerful participant, it can be it very difficult for students to disagree with a reading that might be far removed from their own individual response. This power differential in the classroom yields a typically 'manufactured reading' (Giovanelli and Mason, 2015, p. 42).

Finally, the physical layout of the classroom contains a number of objects that can be primed as salient by the teacher and therefore accepted by students as important elements in the Common Ground. These entities may include the specific layout of students' working space and the subsequent opportunities they have to discuss ideas with peers, and the design of the classroom, for example in the types of displays that a teacher has chosen, and in the highlighting of examination board assessment objectives and marking criteria. All of these are important material aspects that may enable or constrain certain kinds of pedagogical practice (Kress et al., 2005).

\section{Visual representations, literature and pedagogy}

In this article, I follow Mitchell (1994) in defining a visual representation as a deliberate and conscious act of depicting a response to an external stimulus through 
the use of pictures. A general starting point for my discussion in this article is the idea that visual representations can provide an insight into ways in which children perceive and understand events (Thomas and Silk, 1990). Visual representations also allow for more nuanced symbolisations of meaning since typically they present versions of reality that offer greater specificity than their linguistic counterparts (Stenning and Oberlander, 1995). For example, the linguistic term 'house' will have a fairly schematic and generic referent but its corresponding visual representation will usually present its elements in sharper and more specific ways, such as the shape and number of any windows, the colour of the bricks, and the spatial relationship between the house and its immediate physical context and so on ${ }^{1}$. Furthermore, since drawings preceded human speech in a similar manner to gestures (Vygotsky, 1986), visual representations draw largely on similar affordances and limitations of the human body within the visual-spatial domain. Within the curriculum, visual representations can be an important tool to develop interpretations and externalise meanings in a variety of subjects (Matthews, 2003; Hope, 2008, Ainsworth et al., 2011). In English classrooms, teachers have used visual representations to develop reading pedagogies that enable students to exploit the full range of affordances of the visual mode (Millard, 2003), make connections between visual representations and their home background and culture (Pahl, 2006), and provide a theoretical platform for exploring the relationship between literature and visual art (Benton, 1992, 2000).

The use of visual representations as a response to written texts is an example of transmediation (Suhor, 1984), the transferring of communicative content from one sign system to another. In the act of transmediating, readers are automatically required to interpret the original sign system (in this case the verbal text) in an upfront 
and explicit manner. Indeed, the process of transmediation itself involves a very precise kind of thinking and meta-cognitive reflection that allows interpretations to subsequently be explained more easily with others (Short et al., 2000).

In the United States, the practice of responding to literature in this way has been made popular through the teaching programme sketch-to-sketch (Harste et al., 1984; see also Whitin, 1996; White and Voss, 2015 for further discussion). Teachers using this method have designed activities that have allowed students to use visual representations as a way of exploring ideas that they would have found difficult to explain using traditional written responses. For example, writing about her own classroom practice with the sketch-to-sketch programme, Phyllis Whitin describes the work of Melanie, one of her students as follows.

'Melanie's story showed me another value of sketching one's understanding of a piece of literature. Melanie did not simply restate ideas by using language from the novel: she was forced to invent her own system of symbols to show her personal interpretation' (Whitin, 1996, p. 12)

I have argued elsewhere (Giovanelli, 2014) that visual representations are a type of virtual embodied learning activity (see also Holme, 2011) allowing students to using diagrams and pictures as a way of expressing abstract concepts, by reconfiguring the physical space of the page or exercise book into conceptual space within which the externalization of thus far implicit knowledge can take place. In this way, visual representations draw teachers' and students' attention both to the embodied nature of meaning and how interpretations can be both similar and different according to 
personal circumstances and culture (Wales, 1990). In each case, what is drawn is inextricably related to an individual's experience in the world as a social actor.

Text World Theory itself emphasises the visual nature of conceptual processing. Standard Text World Theory notation (see Werth, 1999, p. xvi-xvii) makes use of diagrams and visual relationships to show the various dimensions of world-building. The visual nature of the model shares many analogies with what readers do conceptually when they process and understand language (Werth, 1999, p. 8). Indeed cognitive science generally supports the idea that the mind makes sense of experience by constructing rich mental worlds based on sensory imagery, a great deal of which is visual in nature (Bergen, 2012). Susanne Reichl, in her own exploration of how a textworlds approach can support students to reflect on how they construct mental models of fictional worlds through the use of visual representations, argues that the up-front nature of this kind of work permits students the opportunity to "witness their construction processes and become more aware of them... [and] empowers readers to take more control over their reading' (2009, p. 285).

\section{Research design and background}

In the remainder of this article, I discuss a section of student work that formed part of a qualitative study of a series of lessons taught by a secondary English teacher, Laura, to a Year 7 class using William Carlos Williams' poem 'The red wheelbarrow' (Williams, 1923). In this study, Laura worked with me to examine her own practice by using Text World Theory as a form of 'cognitive grammatics' (Giovanelli, 2014), a tool to support and develop her planning of lessons and her understanding of the reading process in the classroom (see Giovanelli, 2016 for full details). 
Laura was interested in linguistics and education, and was keen to explore how teachers might make use of the considerable resources that students bring to reading texts in the classroom, and consequently how they might avoid the temptation of falling back into the role of 'gatekeeper'. During initial discussions, we had talked about the ways in which classrooms were sites where there was a clear imbalance in power, and we had discussed how Text World Theory offered a cognitively plausible reconfiguration of various reader response theories. For example, we discussed how Werth's model shared many similarities with Rosenblatt's transactional theory of reading (Rosenblatt, 1970, 1978), where reading is conceptualised as a transaction between text and reader (see Giovanelli, 2016 for discussion). This model was an appealing one to Laura and she decided to draw on Text World Theory's emphases on the importance of readers' background knowledge and the visual nature of worldbuilding to support her teaching. Laura was particularly interested in how visual representations might be used at an initial stage of transaction with a text to promote a more personal and less teacher-led response. To this end, she developed a teaching plan similar to that advocated by Benton et al. (1988, p.205) where students were asked to show, monitor and then reflect on their initial responses to the poem. In this instance, these initial ideas were through the medium of visual representations that she hoped would allow students to draw on their own knowledge to articulate their emerging experience of the poem.

Laura had therefore planned to use the visual representations to allow students to make visible how they began to build up fictional worlds from the content of the poem. 'The red wheelbarrow' is, of course, a striking example of imagist poetry and 
is often read as a complex poem that depicts a scene in a richly evocative way (see for example discussion in Rizzo, 2005). Stylistically, however, it contains minimal world-building elements: there is no indication of location or of a time frame, no mention of characters, and the only objects are the wheelbarrow and the chickens. Consequently, Laura believed that it provided a good opportunity for the students to not only engage with the text per se, but also to think about their own schematic knowledge and the meaning-making resources that they brought to the act of reading. In the course of their work, the visual representations produced were accompanied by short pieces of informal writing where students reflected on their reasons for depicting the scene in the poem and considered the type of knowledge they had brought to the reading process. They also discussed their representations and written comments in small groups and so were able to share their responses and build on them through dialogue with others. These discussions were recorded and transcribed, as was a series of interviews with Laura before and after teaching. These initial responses and discussions were later used to inform more focused teaching on William Carlos Williams, the context in which he wrote 'The red wheelbarrow', the literary genre of imagism and the imagist movement, and a discussion of perspective and point of view in the poem (see Giovanelli, 2016 for detailed discussion of Laura's subsequent work with the class). For the purposes of this article, however, my emphasis is on the initial interpretative stage, and I focus exclusively on the visual representations of three students, whose work is typical of the kinds of responses and discussions that the activity generated. In the remainder of this article I therefore draw largely on these visual representations although I do refer briefly to some parts of the students' comments and discussions as well as to observations made by Laura. 


\section{Analysis of visual representations}

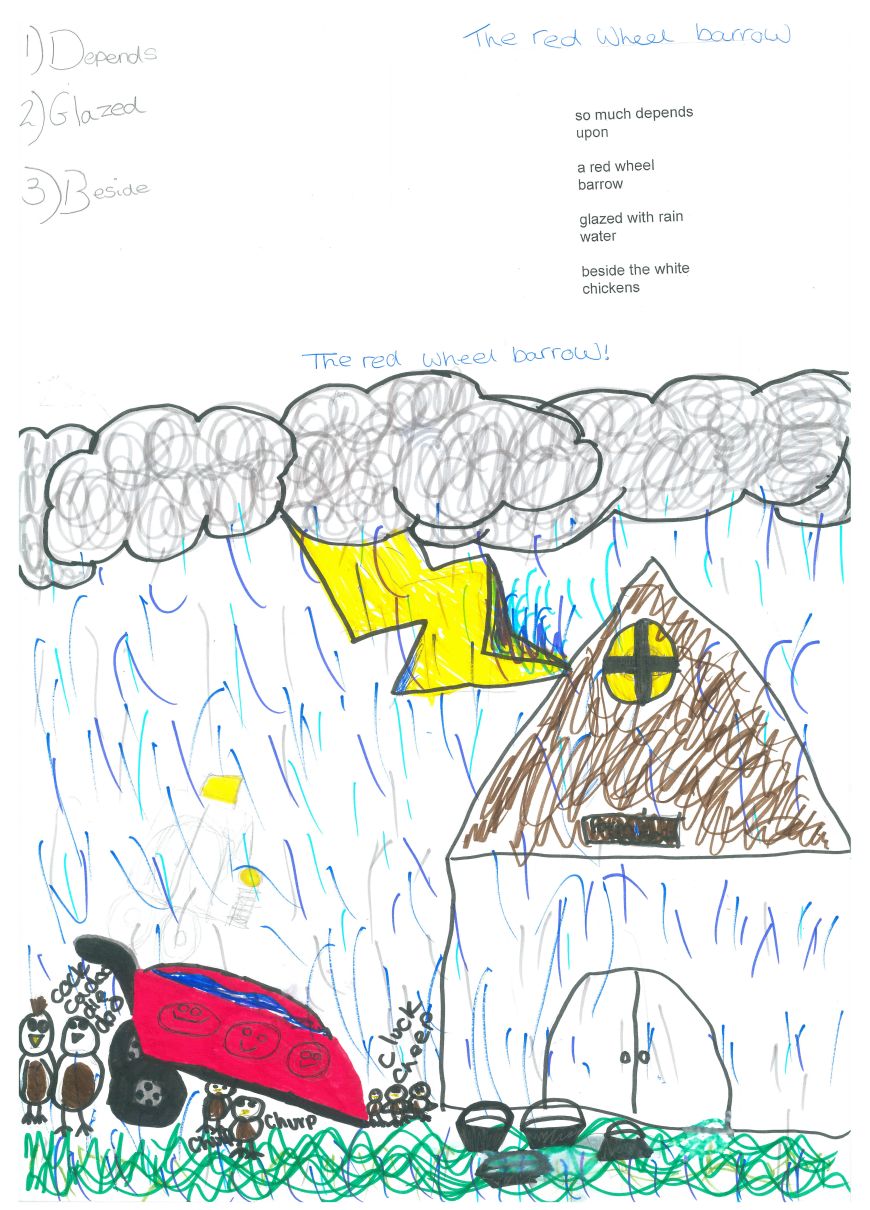

Ella

Ella's visual representation (Figure 1) is striking in the way that it foregrounds a large farmhouse that was not explicitly mentioned in the poem. She had therefore clearly drawn on a specific knowledge schema and had chosen to emphasise this in her response. Indeed her depiction of a large circular window with a black cross towards the top end of the roof was unlike anything else drawn by others in the class. Ella had also made extensive use of colour both in representing the wheelbarrow and in depicting the lightning and clouds at the top of her page. She therefore demonstrated that the poem had evoked a rich scene with which she was able to identify. 
Ella's written reflections on her visual representation revealed that she had visited a farm when she was younger and that the farmhouse there had a circular window, the image of which had stayed with her for some time afterwards. Additionally, she discussed with her peers that she had vivid memories of the window's shape, design and colour, all of which had intrigued her during her visit to the extent that the window became primed automatically in her mind when she read about a farm. Furthermore, she was able to describe how she drew on a very specific additional memory from her childhood that informed her responses to the word 'wheelbarrow':

'When I was younger, me and my friends went down hills in a wheelbarrow. 'Ella, written reflection

The scene depicted by Ella was largely drawing on two very personal events. The memory of the wheelbarrow incident gave rise to a set of embodied meanings that that were located in a specific place, involved a series of physical actions and were situated within social relationships with others. It was also noticeable how Ella's intuitive response to the wheelbarrow drew on a cognitive schema that had been developed through time; that is, the meanings of the word and of the concept had accrued through multiple experiences of riding down hills in a wheelbarrow when she was younger. Ella had responded to the linguistic cue 'red wheelbarrow' in the absence of any other modifying detail by drawing extensively on an episodic memory that had particularly positive memories for her. This memory influenced the drawing of three smiling faces on the body of the wheelbarrow, which she explained represented the happy times that she and her two friends had shared. Indeed in later 
discussion, Ella struggled to reconcile this positive experience with the more negatively oriented mood of the poem that she had articulated through her drawing of the lightning bolt and grey clouds. When pressed by her peers and by Laura, Ella reflected that her own schematic knowledge might be insufficient to fully answer the questions posed by the poem. In other words, she began the process of thinking critically about her transaction with the text.

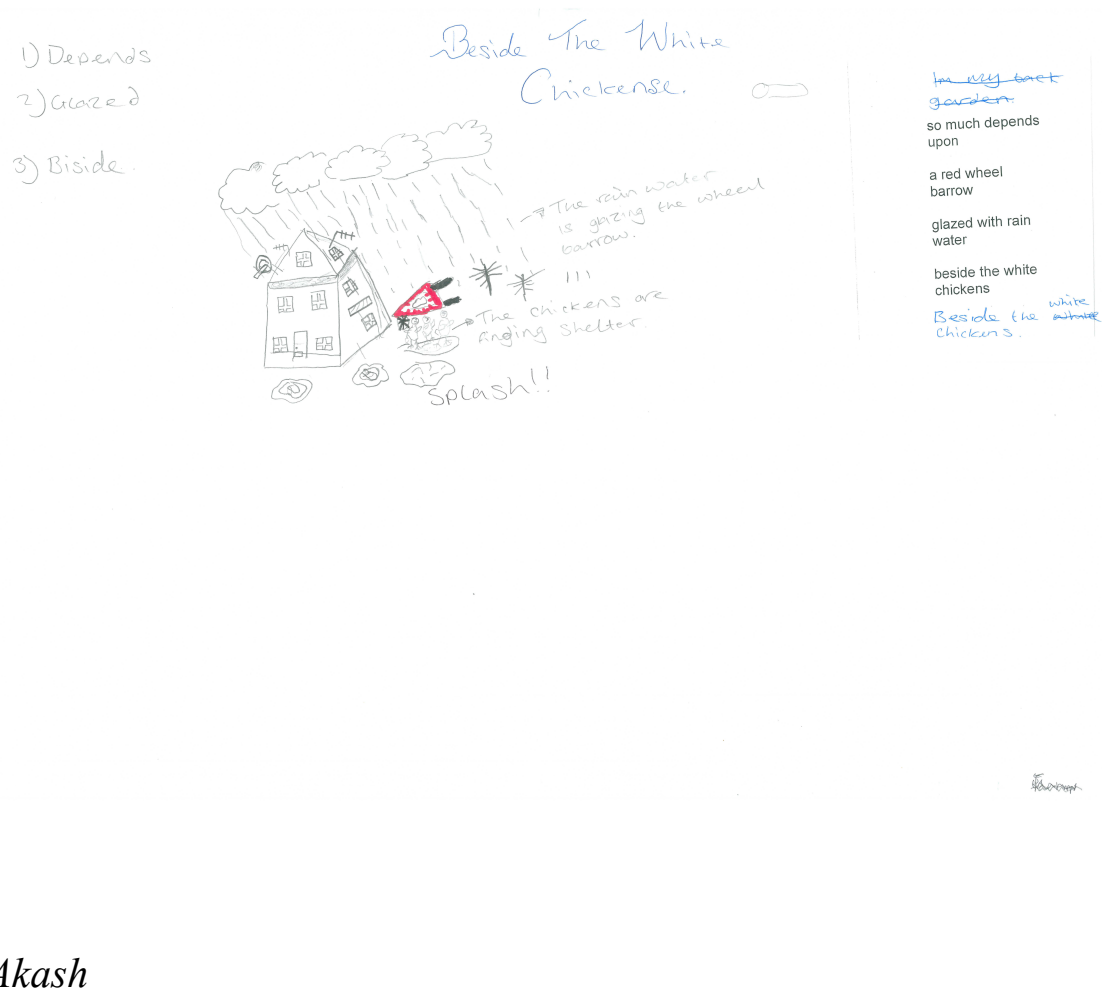

Akash's visual representation (Figure 2) included a similarly foregrounded house. In this instance, his depiction was striking because in both his subsequent written reflection and in his discussion with peers, Akash had emphasised that much of the fictional world he imagined was informed by his culture and background. His family had moved to the UK from Bangladesh four years ago and he had visited the country several times since to visit relatives who still lived there. Akash explained that in Bangladesh, his family had owned a very large farm that had been surrounded by 
trees; the trees therefore became an important part of his representation. It was noticeable, however, that while the trees looked distinctly non-English, his depiction of the farmhouse seemed to synthesise various elements of the UK and Bangladeshi spaces and cultures that he had experienced ${ }^{2}$. Akash thus had a fairly complex set of cognitive schemas from which he was drawing, and his further reflections allowed him to explore with considerable insight why his background had positioned him to respond as he did.

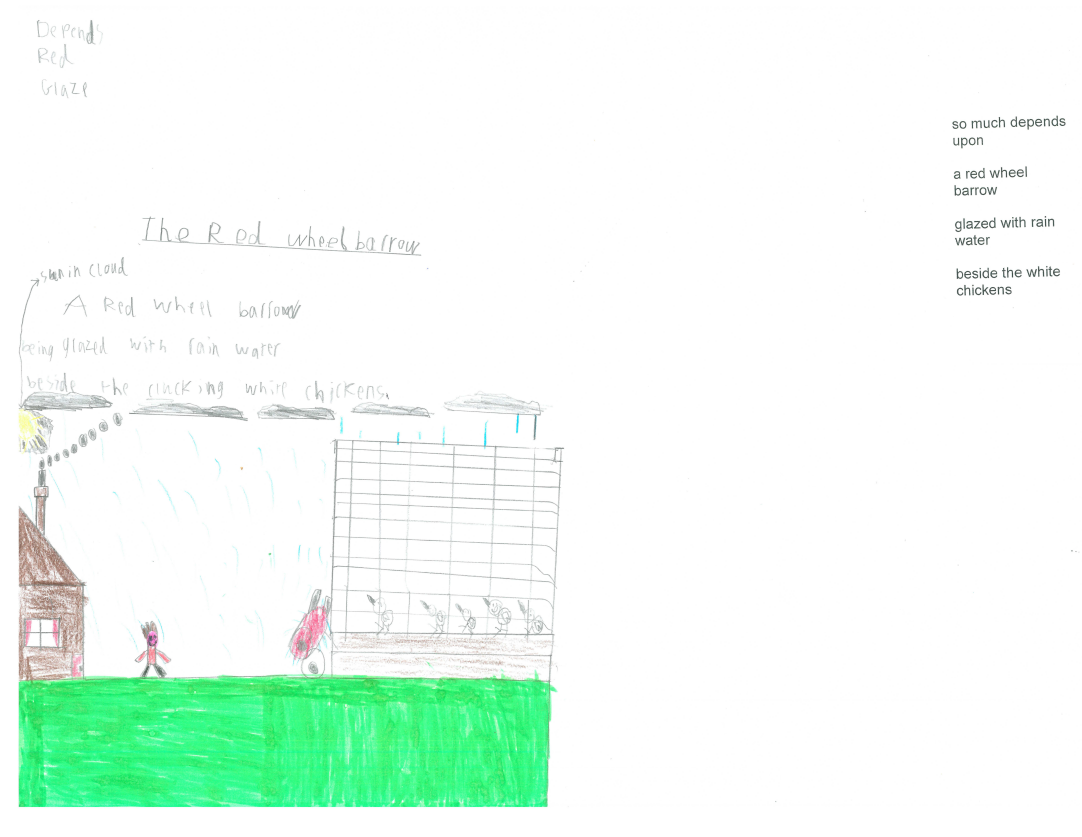

David

In his commentary, David was able to explain how his visual representation (Figure 3) demonstrated the influence his prior experiences had on his own transaction with the poem. In a similar manner to Ella and Akash, his representation showed how he was drawing on a very specific cognitive schema in order to make sense of the poem: in this instance the knowledge that his father kept chickens in their garden. His visual representation depicted the chickens contained in a coop, which differed from the 
more chaotic fictional landscapes presented by Ella and Akash. David also, singularly, included a farmer, not explicitly mentioned in the poem itself. He was later able to explore his decision, explaining:

'I was thinking about the character of the farmer, who might be worried about the chickens and needed to organise the farm. The farmer needed his wheelbarrow for work but he had borrowed it and he said he wouldn't get it wet.' David, written reflection

David's identification with the fictional world included the fleshing out of motivations for this character that he inferred from his own knowledge in the context of imagining the fictional space. In this instance, David imagined a character (probably influenced by his father) who was concerned enough to ensure that the chickens were locked away and the wheelbarrow safely placed against the chicken coop. These imaginative leaps are continuous with what is known as psychological projection (Mar and Oatley, 2008), the ability that readers have to project themselves into the imagined minds of fictional constructs who are perceived and understood in exactly the same way as other salient beings. From a text-worlds perspective, Stockwell (2009) uses the term mind-modelling to explain the capacity that readers have to build cognitive models of characters' thoughts, motivations and desires, informed both by textual detail and their own innate understanding of what it is like to have a consciousness and experience emotions. David thus shows how in even emergent responses to a literary text, readers may mind-model the belief systems of characters they have inferred as being present in the fictional world. In this instance, David's visual interpretation not only made his own response to the poem explicit but 
also allowed him to share and discuss his thoughts on how and why he had imagined the anxieties and concerns of the farmer in this way.

\section{Discussion}

Laura's planning and her students' responses demonstrate how a discussion of the classroom using Text World Theory can offer a way of conceptualising and exploring the richly nuanced relationship between texts, readers and reading contexts as well as the social structure of the classroom within which such transactions occur. I believe that the use of visual representations as part of a methodological framework grounded in Text World Theory raises two discrete but interrelated implications for classroom pedagogy. First, the nature of Text World Theory itself offers a cognitively and socially informed way of conceptualizing and discussing the unique relationships that exist between teachers and their students within the hierarchy of the classroom. Second, and consequently, the work produced by Laura's students offered a way of encouraging discussion of and reflection on the reading process in a manner that mitigated this hierarchy and the potential for teachers to fall back into mediating access to texts and placing constraints on students' interpretations.

As well as offering them the opportunity to enjoy the poem and engage with it in their own terms as a way of developing personal and critical responses, the use of visual representations provided the students with ways of examining the active role a reader plays in the making of meaning. The work produced became a way of anchoring meaning in a way that demonstrated the inherently complex and varied range of resources that the students brought to a reading experience in their transaction with 
the text. In the examples discussed, these resources were drawn from a range of personal and social experiences in the form of embodied memories and various other cognitive schemas from which readers drew on. Laura's planning and teaching allowed this background knowledge to provide a starting point for further exploration and development of ideas in a non-threatening way, and reduced the students' reliance on her. Indeed in reflecting on their work, Ella, Akash and David all showed the existence of a bi-directional relationship between the discourse-world and the textworlds they had created. In other words, they drew on discourse-world knowledge as part of their transactions but the mental representations that they produced fed back to, and were impactful on, their discourse-world selves. This bi-directionality was evident in the feelings and emotions that the visual representations and subsequent discussions provoked that were indicative of an aesthetic, lived through experience of a literary text (Rosenblatt 1970).

In addition, a convenient by-product of this work was the meta-reflective nature of the task, which enabled the students to engage with and think about their own learning and about their own sense of what being a reader entailed. The use of visual representations and the process of transmediation offered ways of allowing students to respond to texts and critically engage with the reading process in a way that conventional written responses might not have facilitated. Subsequent discussions also facilitated an understanding of the affordances and limitations of the students' own clearly marked roles as discourse-world participants within the specific and situated reading context of the classroom. 
The visual representations examined in this article can therefore be viewed and understood as explicit markers of text-world creation and of learning. Furthermore, the visual representations subsequently became important discourse-world entities as physical, material objects in their own right. That is, they become prominent and legitimised salient contextual entities alongside other participants and objects in the classroom, and were explicitly used by the students in discussing their responses and their learning.

It should be noted, however, that Laura had thought about and planned carefully for the use of visual representations as part of her teaching methodology. Clearly, there are a number of issues to consider regarding the use of visual representation to support the teaching of literature; in the following section of this article, I outline some of these issues and explain how Laura had had attempted to mitigate any possible problems.

One of the key issues raised by those studying the visual representations of young children is that they often draw 'what they know not what they see' (Wales, 1990, p.144). In other words, there may be too much self-projection into the text to the extent that the richness that the text holds becomes secondary to the children. Another related concern, this time from the opposite end of the spectrum, is that young readers are necessarily less experienced not just in the process of reading but in life experiences in general. Consequently, the cognitive schemas through which they see and understand the material world are relatively limited, and will, of course, be bound by what they feel is appropriate to draw on in the classroom context. Furthermore, the extent to which visual representations might be successful in expressing meaning will 
depend on an individual child's technical expertise in drawing just as much as on the relative richness of background knowledge and experience that they bring with them to the act of reading. Additionally, the classroom with its complex web of social relationships, interactions and peer pressures could lead to problems within the activity itself as students might feel either self-conscious about their artistic skills or else find it difficult to establish a personal voice. As Gill Hope notes about the potential drawback of using drawings to develop responses to poetry:

'The sharing of emotional responses can be a source of social bonding, developing empathy and delight, but it can also inadvertently be a vehicle for exclusion, embarrassment and even derision' (Hope, 2008, p. 90)

In order to mitigate some of these limitations, Laura had planned carefully, although of course that is not to say that these issues completely disappeared. However, the triangulation of the visual representations with the students' writing, their discussions, the interviews with Laura, and my own researcher's field notes facilitated a much richer interpretation of the students' initial work. Equally, the use of Text World Theory as a framing pedagogical and analytical methodology allowed for a systematic understanding of the classroom context, and as previously noted, enabled Laura to reflect on any potential problems that hierarchies - including those between the students themselves - might present. Crucially, since the focus for the use of visual representations was not on unlocking some received meaning or analysing the poem line by line but rather on developing an emerging emotional and affective response to the poem, the activity offered a starting point for additional reflection, and metareflection. 
Another important point relates to the fact that although the students explained and explored their visual representations, an adult researcher undertook the analysis and interpretation of the data. Despite the clear meta-cognitive focus of this article, there are clearly limitations on what can be inferred or understood from any descriptive account of meaning, either verbal or visual. My purpose here, however, has been to demonstrate the usefulness of visual representations as a way of developing a less prefigured personal response and to provide further potential avenues for classroom discussion, rather than to offer the model as presenting an absolute window into the working mind.

Laura's work offered her a starting point to gain information about students' learning and to facilitate future planning. In subsequent discussions, she revealed that she had identified some further important pedagogical implications of her work with the group. She believed that the students' visual representations, written responses and further ideas generated through feedback and shared talk with their peers formed initial responses to the poem that with careful planning and thought could be developed into more analytical and mature pieces of written work. Indeed she saw the potential to build on this initial work to teach students how to critically examine other contextual factors and therefore assimilate historical, literary and biographical contexts into a response to poetry that moved beyond the simply personal. She also valued the inherently critical nature of the work which encouraged students to see how they could explore the inter-connectedness of different kinds of reading practices and debate the merits of different kinds of authority in the classroom. Reflecting on her teaching, Laura believed that her strategies were successful. Her goals were to facilitate emotional and personal connections with texts and to encourage students to 
develop a critical stance towards the nature of reading, both of which she felt that she had successfully managed. For example, in discussing the use of lightning in Ella's visual representation, Laura explained how Ella had been encouraged to explore her interpretation given the fact that lightning is not mentioned in the poem and consequently think about her role as a creative reader. This discussion naturally led on to a consideration of genre and reader positioning, and raised important questions about literary reading and the classroom such as the role and nature of authorial intention, and the status and responsibility of the teacher as a shaper (or not) of meaning.

Finally, it is worth reiterating that the activities and discussion above have focused exclusively on describing and analysing the emerging processes of interpretation and reading that acted as entry points to enable more detailed textual analysis. It is also important to stress that the emphasis on students' background experiences and knowledge as elements in the shaping of meaning does not in any way suggest that readings should not be accountable to the text itself. In fact, as I have already mentioned, a strong focus on textual design and an appeal to text-drivenness that underpins Text World Theory informed Laura's subsequent teaching so that she was able to ask the students to explain their ideas in the discussions that followed. For example, the students had almost universally remarked that 'so much depends on' suggested a particular perspective (whether that of Williams as poet or of an alternative narrating voice) and were consequently encouraged to think about to whom the point of view belonged and why this perspective might frame the opening of the poem. Laura also pushed the students to see how text-immanent cues might be responsible for their early responses and how returning in more detail to these cues 
might help to expand and revise their original ideas. David was subsequently able to consider how his attention was drawn to 'a red wheelbarrow' since its position after 'so much depends on' and before two post-modifying phrases was an obvious example of foregrounding. The fact that David had signaled this emphasis in his visual representation demonstrates how the principle of attention operates in literary texts (Stockwell, 2009), and specifically offers a way of accounting for an important aspect of Williams' style and the demands that imagist verse places on a reader. Arguably, this foregrounding also provides explicit textual evidence to explain why so many of the students targeted the wheelbarrow and used it to trigger schematic knowledge. It also, of course, raises an important question regarding just how much embellishment was required of the students when reading the poem, as well as how their idiosyncratic responses might in some cases need to made more focused on the text. For example, David's response on character clearly moves into territory that moves considerably away from Williams' explicit representation of the scene. In this instance, he arguably needs to reflect on the limitations of a less text-immanent reading, and this is also an important concern for the teacher.

\section{Conclusions}

Whilst previous studies have shown the value of using visual representations in the classroom, this article frames the use of visual representations within Text World Theory as a way of understanding the classroom itself. It may therefore serve as a model for encouraging students to develop their experiences with literary texts in a way that foregrounds the role of their own embodied knowledge and facilitates making implicit knowledge explicit and open to intra-group discussion. It allows 
teachers to view the classroom as a particularly complex social structure that is very different to a solitary reading event, and to be mindful of the ways in which entities and objects can influence the kinds of interpretations that are perceived as having value by teachers and students alike.

Laura's work demonstrated that encouraging readers to produce responses to literary texts, and then to talk about those representations, offered a way of developing students' sensitivities to the fact they have an active role to play in meaning-making. It also provided a teaching methodology that enabled her to even out the inherently unequal nature of the social structure that underpins most classroom discourse and helped to draw attention more explicitly to some of the constraints that might be applied by a teacher. As such, it offered a way of avoiding the pre-figuring of meaning that so can easily occur in the classroom.

\section{Notes}

${ }^{1}$ Although a visual representation of a house will also be schematic to some extent, a HOUSE schema may vary considerably according to an individual's life experiences and cultural background. My argument here is that a visual representation allows for greater specificity in accounting for schematic nuances in a way that the linguistic cue 'house' simply cannot afford.

${ }^{2}$ Akash was not the only member of the class who had moved to the UK from another country but surprisingly he was the only member who seemed to draw extensively on two different cultural domains of knowledge.

\section{References}


AINSWORTH, S., PRAIN, V. and TYTLER, R. (2011) Drawing to learn in Science.

Science, 333. 1096-1097.

ALSUP, J. (2015) A Case for Teaching Literature in the Secondary School: Why

Reading Fiction Matters in an Age of Scientific Objectivity and Standardization. New York, NY: Routledge.

BENTON, M. (1999) Unweaving the rainbow: Poetry teaching in the secondary school 1. Oxford Review of Education, 25.4, 521-531.

BENTON, M. (2000) Studies in the Spectator Role: Literature, Painting and Pedagogy. London: Routledge.

BENTON, M., TEASEY, J., BELL, R. and HURST, K. (1988) Young Readers Responding to Poems. London: Routledge.

BERGEN, B. (2012) Louder Than Words: The New Science of How the Mind Makes Meaning. New York, NY: Basic Books.

CLARK, B., GIOVANELLI, M. and MACRAE, A. (2015) Lang-Lit From A to BA: Student Backgrounds and First Year Content. http://eprints.mdx.ac.uk/14424/1/clarkgiovanellimacrae_2015_Lang-Lit_AtoBA.pdf. (accessed $16^{\text {th }}$ April 2016)

KIDD, D.C and CASTANO, E. (2013) Reading literary fiction improves theory of mind. Science, 342. 377-380.

CLARK, C. (2011) Setting the Baseline: The National Literacy Strategy Trust's First Annual Survey into Reading. London: National Literacy Trust.

CLARK, C. and RUMBOLD, K. (2006) Reading for Pleasure: A Research Overview. London: National Literacy Trust.

CLIFF HODGES, G. (2010) Reasons for reading: why literature matters. Literacy, 44.2, 60-68. 
CREMIN, T. (2007) Revisiting reading for pleasure: delight, desire and diversity. in K. Goouch and A.Lambirth (Eds.) Understanding Phonics and the Teaching of Reading: A Critical Perspective. Berkshire: McGraw Hill, pp.166-190.

DJIKIC, M., OATLEY, K., ZOETERMAN, S. and PETERSON, J.B. (2009) On being moved by art: How reading fiction transforms the self. Creativity Research Journal, 21.1, 24-29.

DUNGWORTH, N., GRIMSHAW, S., McKNIGHT, C. and MORRIS, A. (2004) Reading for pleasure?: A summary of the findings from a survey of the reading habits of Year 5 pupils. New Review of Children's Literature and Librarianship, 10. 169188.

EDWARDS, A., and WESTGATE, D.P.G. (1994) Investigating Classroom Talk, $2^{\text {nd }}$ edn. London: Routledge.

FAIRCLOUGH, N. (2014) Language and Power, $3^{\text {rd }}$ edn. London: Routledge.

GAVINS, J. (2007) Text World Theory: An Introduction. Edinburgh: Edinburgh University Press.

GIOVANELLI, M. (2014) Teaching Grammar, Structure and Meaning: Exploring Theory and Practice for Post-16 English Language Teachers. London: Routledge.

GIOVANELLI, M. (2016) Text World Theory as cognitive grammatics: A pedagogical application in the secondary classroom. in J. Gavins and E. Lahey (Eds.), World-Building: Discourse in the Mind. London: Bloomsbury Academic, 109-126.

GIOVANELLI, M., and MASON, J. (2015) 'Well I don't feel that': Schemas, worlds and authentic reading in the classroom. English in Education, 49.1, 41-55.

GOODWYN, A. (1997) Developing English Teachers: The Role of Mentorship in a Reflective Profession. Buckingham: Open University Press.

GOODWYN, A. (2010) The Expert Teacher of English. London: Routledge. HARSTE, J.C., SHORT, K.G., w/BURKE, C.L. (1984) Creating Classrooms for Authors. Portsmouth, NH: Heinemann. 
HENNESSEY, J. and MCNAMARA, P.M. (2011) Packaging poetry? Pupils perspectives of their learning experience with the post-primary poetry classroom. English in Education, 45.3, 206-223.

HOLME, R. (2012) Cognitive linguistics and the second language classroom. TESOL Quarterly, 46.1, 6-29.

HOPE, G. (2008) Thinking and Learning Through Drawing in Primary Classrooms. London: Sage Publications.

JOHNSON, D. (2012) Transportation into a story increases empathy, prosocial behavior, and perceptual bias toward fearful expressions. Personality and Individual Differences, 52.2, 150-155.

KRESS, G., JEWITT, C., BOURNE, J., FRANKS, A., HARDCASTLE, J., KONES, K. and REID, E. (2005) English in Urban Classrooms: A Multimodal Perspective on Teaching and Learning. Abingdon: Routledge.

MAR, R., and OATLEY, K. (2008) The function of fiction is the abstraction and simulation of social experience. Perspectives on Psychological Science, 3.3, 173-192. MASON, J. (2015) Narrative interrelation, intertextuality, and teachers' knowledge about students' reading. in M.Giovanelli and D. Clayton (Eds.) Knowing about Language: Linguistics and the Secondary English Classroom. London: Routledge, $162-172$.

MATTHEWS, J. (2003) Drawing and Painting: Children and Visual Representation. London: Sage Publications.

EDWARDS, D. and N. MERCER (1987) Common Knowledge: the Development of Understanding in the Classroom. London: Methuen.

MILLARD, E. (2003) Towards a literacy of fusion: new times, new teaching and learning?. Reading, 37.1, 3-8. 
MITCHELL, W. J. T. (1994) Picture Theory: Essays on Verbal and Visual

Representations. Chicago, IL: University of Chicago Press.

PAHL, K. (2006) Birds, frogs, blue skies and sheep: an investigation into the cultural notion of affordance in children's meaning making. English in Education, 40.1, 20-35. REICHL, S. (2009) Cognitive Principles, Creative Practices: Reading English at University. Vienna: Vienna University Press.

RIZZO, S. (2005) Remembering race: extra-poetical contexts and the racial other in 'The red wheelbarrow'. Journal of Modern Literature, 29.1, 34-54.

ROSENBLATT, L. (1970) Literature as Exploration. London: Heinemann.

ROSENBLATT, L. (1978) The Reader, The Text, The Poem: The Transactional

Theory of the Literary Work. Carbondale and Edwardsville, IL: Southern Illinois University Press.

SHORT, K. G., KAUFFMAN, G., and KAHN, L. H. (2000). 'I just need to draw': Responding to literature across multiple sign systems. The Reading Teacher, 54.2, $160-171$.

SNAPPER, G. (2013) Exploring resistance to poetry in Advanced English studies. in S. Dymoke, A. Lambirth, A. Wilson (Eds.) Making Poetry Matter: International Research on Poetry Pedagogy. London: Bloomsbury, pp.31-45.

STENNING, K., and OBERLANDER, J. (1995) A cognitive theory of graphical and linguistic reasoning: Logic and implementation. Cognitive Science, 19.1, 97-140. STOCKWELL, P. (2009) Texture: A Cognitive Aesthetics of Reading. Edinburgh: Edinburgh University Press.

SUHOR, C. (1984) Towards a semiotics-based curriculum. Journal of Curriculum Studies 16.3, 247-257. 
SULLIVAN, A. and BROWN, M. (2015) 'Reading for pleasure and progress in vocabulary and mathematics' British Educational Research Journal' 41. 971-991. SUMMERS, A. (1991) Unofficial stories in the classroom. English in Education, $25.2,24-30$.

VAN DIJK, T. (2009) Society and Discourse: How Social Contexts Influence Text and Talk. Cambridge: Cambridge University Press.

VYGOTSKY, L. (1986) Thought and Language, $2^{\text {nd }}$ edn. Cambridge, MA: MIT Press.

WALES, R. (1990) Children's pictures. in R. Grieve and M. Hughes (Eds.)

Understanding Children. Oxford: Blackwell, pp. 140-155.

WERTH, P. (1999) Text Worlds: Representing Conceptual Space in Discourse.

London: Longman.

WHITE, A., and VOSS, M. (2015) 'It's a sad, sad story': Teaching emotional connections and tone in literature. The Educational Forum, 79.3, 213-229. WHITIN, P. (1996) Sketching Stories, Stretching Minds: Responding Visually to Literature. Westport, CT: Greenwood Publishing. WILLIAMS, W.C. (1923) Spring and All. Paris: Contact Publishing. XERRI, D. (2013) Colluding in the 'torture' of poetry: Shared beliefs and assessment. English in Education, 47.2, 134-146.

ZUNSHINE, L. (2006). Why We Read Fiction: Theory of Mind and the Novel.

Columbus, OH: The Ohio State University Press. 